\title{
The Influence of Contextual Aspects in Talent Development: Interaction Between Relative Age and Birthplace Effects in NBA-Drafted Players
}

\author{
Nuno Leite ${ }^{1,2 *}$, Jorge Arede ${ }^{1}$, Ximing Shang ${ }^{2}$, Julio Calleja-González ${ }^{3}$ and \\ Alberto Lorenzo ${ }^{4}$ \\ ${ }^{1}$ Research Centre in Sports Sciences, Health Sciences and Human Development (CIDESD), Vila Real, Portugal, \\ ${ }^{2}$ Department of Sports, Exercise and Health Sciences, University of Trás-os-Montes and Alto Douro, Vila Real, Portugal, \\ ${ }^{3}$ Department of Physical Education and Sport, Faculty of Education and Sport, University of Basque Country, Vitoria-Gasteiz, \\ Spain, ${ }^{4}$ Facultad de Ciencias de la Actividad Física y el Deporte, Universidad Politécnica de Madrid, Madrid, Spain
}

OPEN ACCESS

Edited by: Stephen Seiler,

University of Agder, Norway

Reviewed by:

Daniel Castillo,

Universidad Isabel I de Castilla, Spain Karla De Jesus,

Federal University of Amazonas, Brazil

*Correspondence:

Nuno Leite

nleite@utad.p

Specialty section: This article was submitted to Elite Sports and Performance Enhancement,

a section of the journal

Frontiers in Sports and Active Living

Received: 16 December 2020

Accepted: 19 February 2021

Published: 22 March 2021

Citation:

Leite N, Arede J, Shang X, Calleja-González $J$ and Lorenzo $A$ (2021) The Influence of Contextual Aspects in Talent Development Interaction Between Relative Age and Birthplace Effects in NBA-Drafted

Players.

Front. Sports Act. Living 3:642707. doi: 10.3389/fspor.2021.642707
The aims of this study were two-fold: (1) to inspect separately for the relative age and birthplace effects for players selected in the National Basketball Association (NBA) draft; (2) to explore the interaction among these factors and analyse this interaction in players' career performance. The database was obtained from the official records of the players ( $n=1,738$ ), who were selected during the annual editions of the NBA Draft from 1990 to 2019. The participants' date of birth was analyzed according to the month of birth and divided into four quartiles. The place of birth was compared to the distribution of the general population' places of birth based on different communities' sizes. Chi-square analysis were used to determine if the relative age and birthplace of the players drafted differed in any systematic way from official census population distributions. Cluster analysis and standardized residuals were calculated to analyse the interaction among the contextual factors and the players' career performance. The data revealed that early-born players (Q1 and Q2) were over-represented. Moreover, players born in smaller cities $(<100,000)$ were over-represented. The interaction analysis revealed that the players born in the bigger communities relate mainly with relatively younger players, and clusters that correspond to players born in smaller communities integrated the relatively older players. No differences were found in the players' career performance. Researchers, coaches and practitioners should be aware of the interaction between contextual factors to help nurture the development of sport talent regardless of age-related issues or communities' size.

Keywords: environmental factors, talent development, date of birth, place of birth, interaction, selection, basketball

\section{INTRODUCTION}

A growing core of scientific research has shown that contextual factors play a key role in talent development (Baker et al., 2009; Rees et al., 2016; Williams et al., 2020). In particular, the role of contextual variables such as the date of birth (Castillo et al., 2019; De la Rubia et al., 2020a), and the place of birth (Rossing et al., 2015; Pennell et al., 2017; Wattie et al., 2018) have been consistently associated with improved chances of attaining elite sport. 
The biased distribution of the dates of birth, known as the relative age effect (RAE), has been confirmed in several studies in the field of sports sciences and other domains, such as in academic performance (for references see Nakata et al., 2017). In that way, evidence confirm this phenomenon, in which individuals born earlier in the selection year relative to a predetermined cut-off date (e.g., January 1-December 31) are often overrepresented compared to those born later in the same selection year (Fumarco et al., 2017; please see De la Rubia et al., 2020a). In this sense, relatively older athletes are systematically associated with higher stature and better aerobic capacity, endurance and speed, what provides them with a competitive advantage in physical performance (Rada et al., 2018). Related to physical advantages, critical in childhood and adolescence, the relatively older athletes are generally considered to have greater potential and consequently with an increased likelihood of being selected to play and practice in a more challenging environment, and to be supervised by more experienced coaches, what may eventually lead to improved feedback mechanism and competitiveness (Musch and Grondin, 2001; Bezuglov et al., 2019). In contrast, relatively late-born athletes are more unlikely to obtain similar early opportunities, which will inevitably make their road to success more difficult (Arede et al., 2019a).

Scientific evidence in the literature has shown that contextual factors such as the place of birth (known as birthplace effects where the subject was born and grew up during the developmental years, Lidor et al., 2014) also can influence an athlete's likelihood of elite sporting attainment (Côté et al., 2006; MacDonald et al., 2009b; Imtiaz et al., 2014; Turnnidge et al., 2014; Ishigami, 2016; Wattie et al., 2018; Kaida and Kitchen, 2020). In that way, mixed results have been reported for the birthplace effects. For example, early studies (Côté et al., 2006) revealed that athletes born in cities of less than 500,000 inhabitants were more likely to play for professional leagues than athletes born in larger cities. Researchers reported that higher developmental opportunities may be associated with smaller cities, including improved mobility and safety conditions for play and practice, cultural and closer personal relationship between athletes and coaches (Davids and Baker, 2007). Nevertheless, recent studies showed different results as larger cities were just as effective in producing elite athletes in smaller cities (e.g., Schorer et al., 2010). The authors highlighted the fact that bigger cities can offer better-designed and equipped sporting facilities (e.g., arenas, fields, and swimming pools) and more experienced coaches (see Baker et al., 2009; Schorer et al., 2010). Despite such assumptions, the extent to which these trends apply to other sports and sport development systems in other countries remains to be determined. Though some authors have already identified some inconsistencies in the birthplace definition (Rossing et al., 2015), fundamentally due to the differences found among the place of birth, the athlete's place of development, the first club, and the inaccurate interpretation that may arise from this misconception, the fact is that birthplace studies are still scarce and further contributions can be potentially decisive to improve the process of talent identification and development.

Over the past few years, some studies have examined the RAE and the birthplace effects with the same group of athletes (Côté et al., 2006; Baker et al., 2009; MacDonald et al., 2009a; Lidor et al., 2014; Turnnidge et al., 2014; Ishigami, 2016). However, most of these studies analyzed these contextual factors on limited geographical areas. In fact, there is an important gap to cover in the scientific literature that could be bridged in comparing youth sport policies and developmental systems. For instance, the development of high-level athletes in European countries is mainly based on club teams, while in the USA, they emerge from the school system. Moreover, while prior studies have confirmed the influence of these factors in a number of different sports in various countries, they have not demonstrated how these aspects interact (Bruner et al., 2011) and affect the chances of playing in a professional league like the NBA (National Basketball Association). The odds of a pre-high school player being chosen to play at a professional level in the NBA are intrinsically low, and only a small part of these players is selected through the NBA Draft (Koz et al., 2012). This is competitive event, where the league franchises obtain the professional rights of players who do not yet have a contract with any team in the competition. A total of 60 players are selected each year and the order of selection of these players is stipulated by the lottery draft that takes in account the teams' final balance of victories and defeats from the last NBA season.

To the best of our knowledge, this is the first study dedicated in examining the long-term effect of both contextual factors, in the NBA career performance. Thus, the aims of this study were twofold: (1) to inspect separately for the RAE and birthplace effects for USA players and for players born in the European countries; (2) to explore the interaction among these contextual factors and the long-term effect in the players' career performance. Drawing upon existing literature in sport sciences, it was hypothesized that the RAE and the birthplace effects influence the likelihood of being selected to play in the NBA; and, that the interaction among these factors exist and that it can also be observed in the players' career performance.

\section{METHODS}

\section{Participants}

The database was obtained from the records of all players $(n=$ 1,738 ), selected during the annual editions of the NBA Draft, from 1990 to 2019. The database included players born in 67 different countries, 1,389 players born in the USA, 237 born in the European countries, 37 in African countries, 44 in South American countries, and finally 29 in Asian countries (Figure 1 and Table 1).

The players who were selected in the NBA Draft but failed in accumulating a significant experience in the league, i.e., never played in any NBA team or did not completed 1 full and consecutive season (minimum 82 games) were not considered for analysing the second aim of this study, i.e., the interaction among the contextual factors and the players' career performance. The present study was approved by the institutional research ethics committee (UID04045/2020) and conformed to the recommendations of the Declaration of Helsinki, with the Fortaleza actualization (Hellmann et al., 2014). 


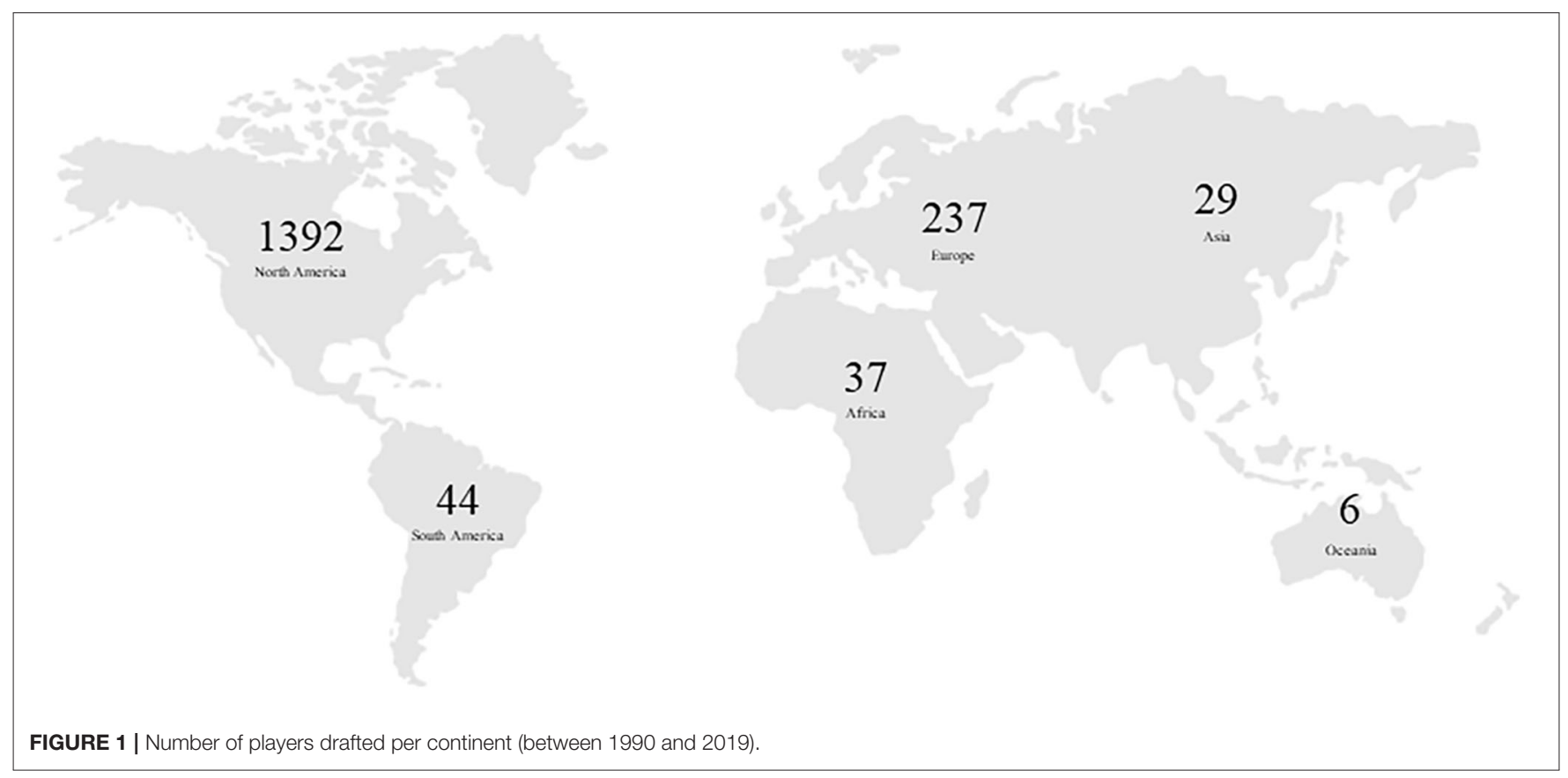

TABLE 1 | Number of players drafted per country (between 1990 and 2019).

\begin{tabular}{lc}
\hline Country & \# Players \\
\hline USA & 1,389 \\
France & 30 \\
Serbia & 26 \\
Bosnia-Herzegovina & 17 \\
Spain & 16 \\
Lithuania & 14 \\
Croatia, Germany, Slovenia & 12 \\
Greece, Turkey & 11 \\
Brazil, Nigeria, Ukraine & 10 \\
Montenegro & 9 \\
England, Senegal & 8 \\
China, Russia & 7 \\
Italy, Latvia & 6 \\
Czechoslovakia, Israel & 5 \\
Argentina, Australia, Belgium, Congo, Georgia, Switzerland, & 4 \\
Sudan, Sweden, Dominican Republic & \\
Canada, Finland, Ghana, Haiti, Guadeloupe, Netherlands, Mali, & 3 \\
Poland, Puerto Rico & \\
Egypt, Jamaica, New Zealand, Romania, Trinidad and Tobago, & 2 \\
Zaire & \\
Angola, Austria, Belarus, Cape Verde, Central African Republic, & 1 \\
Denmark, Estonia, Guinea, Hungary, India, Iran, Japan, Korea, & \\
Uzbekistan, Venezuela, Taiwan, South Africa, Saint Vincent and \\
the Grenadines, Mexico, Luxembourg & \\
\hline
\end{tabular}

\section{Procedure}

Official players' data collection was completed in two consecutive steps. First, the date and place of birth of the players selected to the NBA Draft, were collected from the Basketball reference website (https://www.basketball-reference.com/). Second, individual career stats accumulated in the NBA were collected form the official league website (https://www.nba.com/). The participants' date of birth was first analyzed according to the month of birth. The cut-off date was January $1^{\text {st }}$. Thus, the year was divided into four quartiles: Q1, January $1^{\text {st }}$-March $31^{\text {st }}$; Q2, April $1^{\text {st }}$-June $30^{\text {th }}$; Q3, July $1^{\text {st }}-$ September $30^{\text {th }}$; and Q4, October $1^{\text {st }}$-December $31^{\text {st }}$ (Figure 2).

The place of birth was compared to the distribution of the general population' places of birth according to different city or communities' sizes categorization (Côté et al., 2006), into 1 of 8 census population categories: (1) more than 5,000,000 million of inhabitants; (2) between 2,500,000 and 4,999,999; (3) $1,000,000-2,499,000$; (4) 500,000-999,999; (5) 250,000499,999; (6) 100,000-249,999; (7) 50,000-99,999; (8) less than 50,000 inhabitants.

To investigate the first hypothesis and considering the considerable number of players born in European countries drafted by NBA teams and simultaneously the interest of comparing the RAE and birthplace across countries and continents, we conducted a separate analysis for players born in the USA and born in the European countries. However, the singularity of each European country registration system, the methods of defining demographic maps as well as, the particularities of the territorial organization limited a more comprehensive analysis of the interaction among the RAE and the birthplace also for the players born in European countries (i.e., the second hypothesis). This procedure was also supported by the lack of consistency of the evidence found in several studies examining the birthplace effects in European born players in comparison with, for example USA (Baker et al., 2009; Lidor et al., 2010, 2014; Schorer et al., 2010; Bruner et al., 2011; Rossing et al., 2015). Contextual factors such as cultural differences intra- 


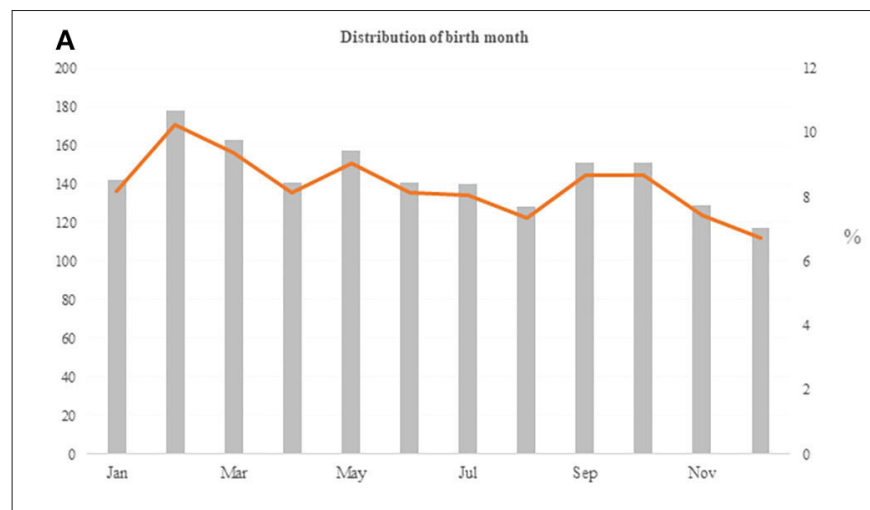

\section{B}

35

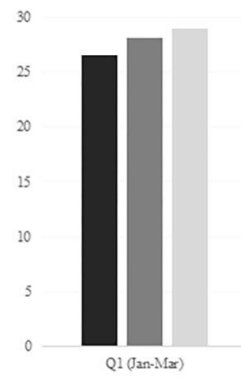

Distribution of birth quarters

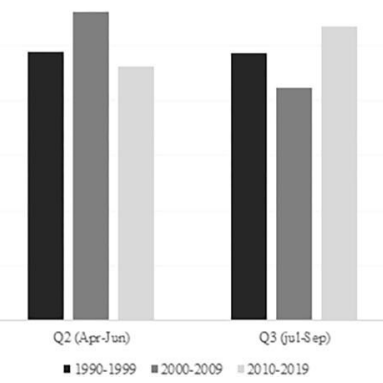

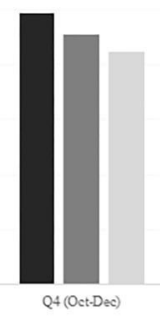

FIGURE 2 | Distribution of (A) birth months (left) and (B) birth quarters according to the decades of the NBA draft (right).

and inter-regional communities within European countries, distances among communities, the number and quality of sport facilities, the number of experts or the competitive depth of a given sport, represented important obstacles that could further justify this inconsistency in European results. For this reason, to proceed with the second hypothesis of this study, we chose to select only the players born in the USA $(n=1,389)$.

\section{Statistical Analysis}

In accordance to the statistical procedures used in previous studies examining the RAE and/or the birthplace (Hancock et al., 2018), we analyzed the differences among the distributions of observed and expected percentages.

After analyzing the variables for skewness, kurtosis, normality distribution through Kolmogorov-Smirnov test, and the equality of variances by Levene test, parametric or nonparametric statistical tests were used when appropriated assuming a confidence level of 0.05 . A chi-square test $\chi^{2}$ was used to analyse de distribution of dates of birth across the 4 quartiles Q1, Q2, Q3, and Q4. Odds ratios (OR) and 95\% confidence intervals (CI) were calculated to determine the odds of a player born in Q1 (JanuaryMarch) playing in the NBA compared to the odds of a player born in Q2, Q3, and Q4. An OR with CI limits (lower and upper) higher than 1 indicates that a disproportionately high number of NBA-drafted players were observed in each quartile compared to that expected due to the general population distribution. Correspondingly, an OR with CI lower and upper limits lower than 1 indicates that a disproportionately low number of drafted players was observed. RAE were compared among the different groups (quartiles) using Wilcoxon and Mann-Whitney $U$ tests.

Similar statistical procedures were used to analyse the differences among the distributions of observed and expected communities' size categories. Thus, $\chi^{2}$, ES, OR, and 95\% CI were calculated to determine the odds of a player born in a smaller community, i.e., $<50,000$ inhabitants playing in the NBA compared to the odds of a player from the remaining categories. For analysing RAE and birthplace effects, we selectively used data from USA's 1990 Data and Statistics and Europe's 2000 Eurostat, as they were the closest possible to the average year of birth of the players included in our selective sample.
Cluster analysis was performed using Ward's methodsquared Euclidian distance as a distance measure-using RAE and birthplace effects quartiles and communities' size. The $\chi^{2}$ test was used to examine between-conditions differences in terms of RAE and birthplace effects. Standardized residuals (e) were used to determine which variable(s) in each category contributed most to the value of $\chi^{2}$. Cells which contained values of standardized residual that were higher than 1.96 ( $\mathrm{e}>1.96)$, were considered influent for the model.

Univariate analysis of variance (ANOVA) test and Tukey's post-hoc test was used in conjunction to examine the differences between clusters. Statistical analyses were performed using SPSS v.25 software (Inc., Chicago, IL, USA) and significant level was set at $p<0.05$.

\section{RESULTS}

Table 2 presents the frequency and percentage distribution of the drafted players' birth quartiles. The $\chi^{2}$ analysis confirmed a biased distribution both for USA and European players $(p=$ 0.005 and $p=0.028$, respectively). For American players, the distribution of the players' birthdates in Q1 (28.2\%) was higher than those in Q2 (23.9\%), Q3 (24.7\%), and Q4 (23.3\%). The analysis of the RAE for players born in European countries revealed similar results, however the higher percentage was observed in Q2 (32.1\%). For USA players, the likelihood of player born is Q1 being selected to play in the NBA yielded an OR higher than $1[\mathrm{OR}=1.236$, CI $(1.044-1.465)]$; similar results were found for European players, as Q1 and Q2 presented an OR higher than $1[\mathrm{OR}=1.148, \mathrm{CI}(0.760-1.734) ; \mathrm{OR}=1.378$, CI (0.924-2.051), respectively].

The distribution of the USA and European players across different communities' size categories are displayed in Table 3. Results confirmed a different distribution in the categories between the USA and European census and the players selected for the NBA Draft. Smaller categories are over-represented in the drafted players, especially with less than 100,000 inhabitants, both for USA and European draftees. Moreover, communities with a population above 1,000,000 yielded an OR lower than 1 . This means that the likelihood for players born in big city to be selected and play in the NBA was lower than for players born in 
TABLE 2 | Descriptive and inferential analysis for dates of birth for USA and European players.

\begin{tabular}{|c|c|c|c|c|c|c|c|c|c|c|c|c|}
\hline \multirow[t]{2}{*}{ Birth quarter } & \multicolumn{6}{|c|}{ USA } & \multicolumn{6}{|c|}{ Europe } \\
\hline & $\mathrm{CDC}^{\mathrm{a}}$ & $\%$ & OR & Cl & $x^{2}$ & $p$ & $E U^{b}$ & $\%$ & OR & Cl & $x^{2}$ & $p$ \\
\hline Q1 (Jan-Mar) & 24.10 & 28.2 (392) & 1.236 & $1.044-1.465$ & 12.888 & $0.005^{\star \#}$ & 24.36 & $27.0(64)$ & 1.148 & $0.760-1.734$ & 9.13 & $0.028^{\$}$ \\
\hline Q2 (Apr-Jun) & 24.96 & 23.9 (332) & 0.944 & $0.794-1.122$ & & & 25.54 & 32.1 (76) & 1.378 & $0.924-2.051$ & & \\
\hline Q3 (Jul-Sept) & 26.43 & 24.7 (343) & 0.913 & $0.770-1.083$ & & & 25.85 & $19.4(46)$ & 0.690 & $0.447-1.065$ & & \\
\hline Q4 (Oct-Dec) & 24.60 & 23.3 (324) & 0.931 & $0.782-1.108$ & & & 24.25 & $21.5(51)$ & 0.855 & $0.556-1.314$ & & \\
\hline
\end{tabular}

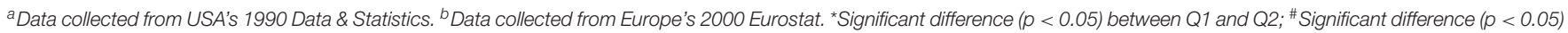
between Q1 and Q4; \$Significant difference ( $p<0.05)$ between Q2 and Q3.

Legend: OR, odds ratio; $\mathrm{Cl}$, confidence interval.

TABLE 3 | Descriptive and inferential analysis for places of birth for USA and European players.

\begin{tabular}{|c|c|c|c|c|c|c|c|c|}
\hline \multirow[t]{2}{*}{ Population size } & \multicolumn{4}{|c|}{ USA } & \multicolumn{4}{|c|}{ Europe } \\
\hline & $\mathrm{CDC}^{\mathrm{a}}$ & $\%$ & OR & Cl & $E^{b}$ & $\%$ & OR & Cl \\
\hline$>5,000,000$ & 23.19 & 0.7 & 0.024 & $0.013-0.045$ & 0.92 & 0.7 & 0.759 & $0.165-3.496$ \\
\hline 2,500,000-4,999,999 & 13.91 & 9.6 & 0.657 & $0.520-0.830$ & 2.30 & 4.2 & 1.862 & $0.987-3.513$ \\
\hline 1,000,000-2,499,999 & 15.65 & 8.5 & 0.501 & $0.395-0.635$ & 11.07 & 9.2 & 0.796 & $0.511-1.242$ \\
\hline 500,000--999,999 & 10.49 & 15.6 & 1.577 & $1.260-1.974$ & 14.61 & 10.9 & 0.715 & $0.475-1.076$ \\
\hline $250,000-499,999$ & 9.12 & 11.9 & 1.346 & $1.054-1.718$ & 14.54 & 12.6 & 0.847 & $0.577-1.244$ \\
\hline 100,000-249,999 & 8.94 & 15.7 & 1.897 & $1.501-2.397$ & 10.23 & 16.7 & 1.759 & $1.251-2.475$ \\
\hline 50,000-99,999 & 0.7 & 13.7 & 2.109 & $1.632-2.726$ & 1.31 & 16.7 & 15.103 & $10.736-21.248$ \\
\hline$<50,000$ & 18.00 & 24.4 & 1.471 & $1.224-1.767$ & 45.02 & 26.8 & 0.447 & 0.335-0.596 \\
\hline
\end{tabular}

a Data collected from USA's 1990 Data \& Statistics. ${ }^{b}$ Data collected from Europe's 2000 Eurostat.

Legend: OR, odds ratio; $\mathrm{Cl}$, confidence interval.

a smaller community. In addition, the likelihood for players who were born in a smaller city (i.e., 50,000-99,999) was higher than the remaining categories [USA OR $=2.109$, CI (1.632-2.726); EU OR $=15.103$, CI (10.736-21.248)].

The cluster analysis established different levels of interaction in terms of birth quartiles, communities' size categories and career stats profiles. Table 4 and Figure 3 displays these interactions where it stands out (i) clusters corresponding to the players born in the bigger communities relate mainly with relatively younger players; (ii) clusters that correspond to players born in smaller communities integrated the relatively older players; (iii) no differences were found in the career stats.

\section{DISCUSSION}

The main aims of this study were two-fold: (1) to inspect separately for the RAE and birthplace effects for players born in the USA and in the European countries; (2) to explore the interaction among these contextual factors and the long-term effect of both these factors in the players' career performance. We found a biased distribution of the birth quartiles, as the number of players born in Q1 or Q2 was higher than that of those born in Q3 or Q4 both for those born in the USA and born in European countries. These results are consistent with previous research confirming an advantage in favor of the earlier born players emerging from the athletic programs of colleges and universities in the United States of America, Canada and European clubs.

The NBA is an extremely competitive professional league, which makes highly demanding the process of preparing and selecting players. The franchises have to choose the best players based on their abilities and potential, but must be able to predict the level of future performance. Thus, the selection process (i.e., the NBA Draft) is highly conditioned by the players' performance and favors the selection of those athletes who were born in the first months of the year and that will have a greater impact on the team's performance (De la Rubia et al., 2020a). In the case of basketball, the presence of the RAE still manifests itself around 20-22 years of age, at the same age category where NBA Draft take place (De la Rubia et al., 2020a). Therefore, there may be a ripple effect that benefits the selection of relatively older athletes, despite it still unknown how it affects the long-term performance of the athlete, that is, in his sports career.

In sports like basketball, the "maturation-selection hypothesis" applies, i.e., relatively elder players are naturally heavier, taller, stronger, and faster than other (Baker and Logan, 2007; Zaric et al., 2020), and can simultaneously benefit from an advantage resulting from being born in an earlier month, but also from an early maturation, to have better opportunities (Arede et al., 2019b). This seems to make sense, given that the anthropometric aspects important factor for the performance in basketball (Teramoto et al., 2017; Zaric et al., 2020). In fact, the results obtained during the annual event hosted by NBA dedicated to assess the players with greatest potential (i.e., NBA Draft Combine) have shown that length-size aspects, such as height, body mass, wingspan, and hand dimensions have the greatest positive correlation with on-court performance in the NBA, in the short and medium term (Teramoto et al., 2017). However, based on present results, we may hypothesize that this initial physical/anthropometric advantage (i.e., the NBA Draft) 
TABLE 4 | Descriptive and inferential analysis for career performance, RAE and birthplace for USA players.

\begin{tabular}{|c|c|c|c|c|c|c|c|c|}
\hline & & $\begin{array}{c}\text { Cluster } 1 \\
n=375\end{array}$ & $\begin{array}{c}\text { Cluster } 2 \\
n=184\end{array}$ & $\begin{array}{c}\text { Cluster } 3 \\
n=189\end{array}$ & $\begin{array}{c}\text { Cluster } 4 \\
n=172\end{array}$ & $\begin{array}{c}\text { Cluster } 5 \\
n=247\end{array}$ & $\begin{array}{c}\text { Cluster } 6 \\
n=222\end{array}$ & $p$ \\
\hline \multirow[t]{4}{*}{ Career performance } & $\% G S$ & $32.6 \pm 30.9$ & $32.9 \pm 29.5$ & $32.8 \pm 31.1$ & $34.3 \pm 30.4$ & $30.8 \pm 29.6$ & $33.3 \pm 31.1$ & 0.924 \\
\hline & MPG & $18.3 \pm 9.0$ & $18.5 \pm 8.4$ & $18.1 \pm 9.0$ & $18.5 \pm 8.6$ & $18.3 \pm 8.2$ & $19.2 \pm 8.7$ & 0.880 \\
\hline & PPG & $18.0 \pm 4.8$ & $17.3 \pm 4.8$ & $18.3 \pm 5.8$ & $17.7 \pm 6.5$ & $17.5 \pm 4.7$ & $18.7 \pm 7.5$ & 0.159 \\
\hline & Rebounds & $8.1 \pm 3.5$ & $8.5 \pm 3.7$ & $8.7 \pm 3.7$ & $8.4 \pm 3.9$ & $8.3 \pm 3.4$ & $8.0 \pm 3.6$ & 0.429 \\
\hline \multirow[t]{4}{*}{ Birth quarter } & Q1 (Jan-Mar) & -6.3 & 12.2 & -7.3 & -7.0 & 3.2 & 6.5 & \\
\hline & Q2 (Apr-Jun) & 1.3 & 0.0 & -6.7 & -6.4 & 2.4 & 7.6 & \\
\hline & Q3 (Jul-Sep) & 3.5 & -6.7 & 8.3 & -0.4 & 1.7 & -7.4 & \\
\hline & Q4 (Oct-Dec) & 2.0 & -6.5 & 6.3 & 14.5 & -7.6 & -7.2 & \\
\hline \multirow[t]{5}{*}{ Birthplace } & $>5,000,000$ & 4.4 & -1.2 & -1.2 & -1.1 & -1.3 & -1.3 & \\
\hline & 250,000-499,999 & -6.7 & 11.9 & 13.9 & -4.5 & -5.4 & -5.2 & \\
\hline & $100,000-249,999$ & -7.5 & -5.3 & 13.3 & -5.1 & -6.1 & 13.2 & \\
\hline & 50,000-99,999 & -7.2 & -5.0 & -5.1 & 11.0 & -5.8 & 14.9 & \\
\hline & $<50,000$ & -9.6 & -6.7 & -6.8 & 8.1 & 23.9 & -7.4 & \\
\hline
\end{tabular}

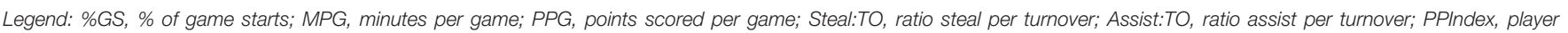
performance index. Data is presented as $M \pm S D$. Bold corresponds to cells which contained values of standardized residual that were higher than 1.96 (e > 1.96).

is circumstantial and does not remain across the professional career; instead, relatively younger players born in Q3 e Q4 (USA) and Q3 (European countries), i.e., may overcome that disadvantage and gradually develop the physical, technical, tactical, and mental skills required to succeed in the NBA (Sampaio et al., 2015). These results are particularly important given that, for the first time, they confirm that in a long-term development perspective, elite basketball seems not to favor the relatively older players.

Previous knowledge about players' potential as well as coaches and scouts' biases, should be considered as another possible reason for our results (Till and Baker, 2020). For example, Mann and van Ginneken (2017) reported that the selection bias could be reduced when scouts watched junior soccer games analyzing the shirt numbers corresponded to the RAE of the players. The authors concluded that the selection bias associated with the RAE can be reduced, if information about age is presented appropriately. Although the RAE investigation is extensive (see De la Rubia et al., 2020b for extensive review on the RAE), many coaches and scouts are not yet fully informed about this phenomenon, and therefore, further investigation and an effective bridge between science and practice is required (Olswang and Prelock, 2015).

The results of our study are consistent with previous literature on birthplace effects, showing that the place where the athlete is born does not hinder the possibility of attaining elite performance (MacDonald et al., 2009b). Interestingly, a great number of players drafted to the NBA born in smaller cities ( $<50,000 ; 24.4$ and $26.8 \%$ for USA and European players, respectively). The same trend has been observed in different professional sports, such as ice hockey, baseball, golf, football, and soccer (Côté et al., 2006; MacDonald et al., 2009a,b; Wattie et al., 2018).

Globally, evidence from our study confirm that smaller communities can match medium and large communities in early opportunities for talent development. While the notion of the "small town effect" has been examined recently, most of the researchers did not find empirical evidence to support that concept in pathways to sport expertise (Pennell et al., 2017). Several explanations for the contribution of communities of this size to the development of talent in sport have already been proposed, among which we underline larger social support by their peers, families, enabling them to develop their skills and also an increased perception of safety in open-spaced areas (MacDonald et al., 2009a). Moreover, these smaller population areas can also foster more supportive relationships between coaches and athletes, and even with the social context that surrounds the sport that favor the feeling of belonging as well as a much more positive learning context. Under such circumstances, young athletes are more likely to develop a positive self-concept and acquire the necessary motivation for a long-term and positive involvement in sport (Moesch et al., 2013). Additional benefits have been associated to smaller communities. In fact, children seem to allocate more time to the multi-faceted process of learning the sport skills that are relevant to their specific sport or being able to practice sport in a less structured environment ("deliberate play"), in such a way that it favors the development of tactical creativity and perceptual and decision-making capacity (Berry et al., 2008; Greco et al., 2010; Memmert et al., 2010; Ford et al., 2011; Leite and Sampaio, 2012; Arede et al., 2019a). 


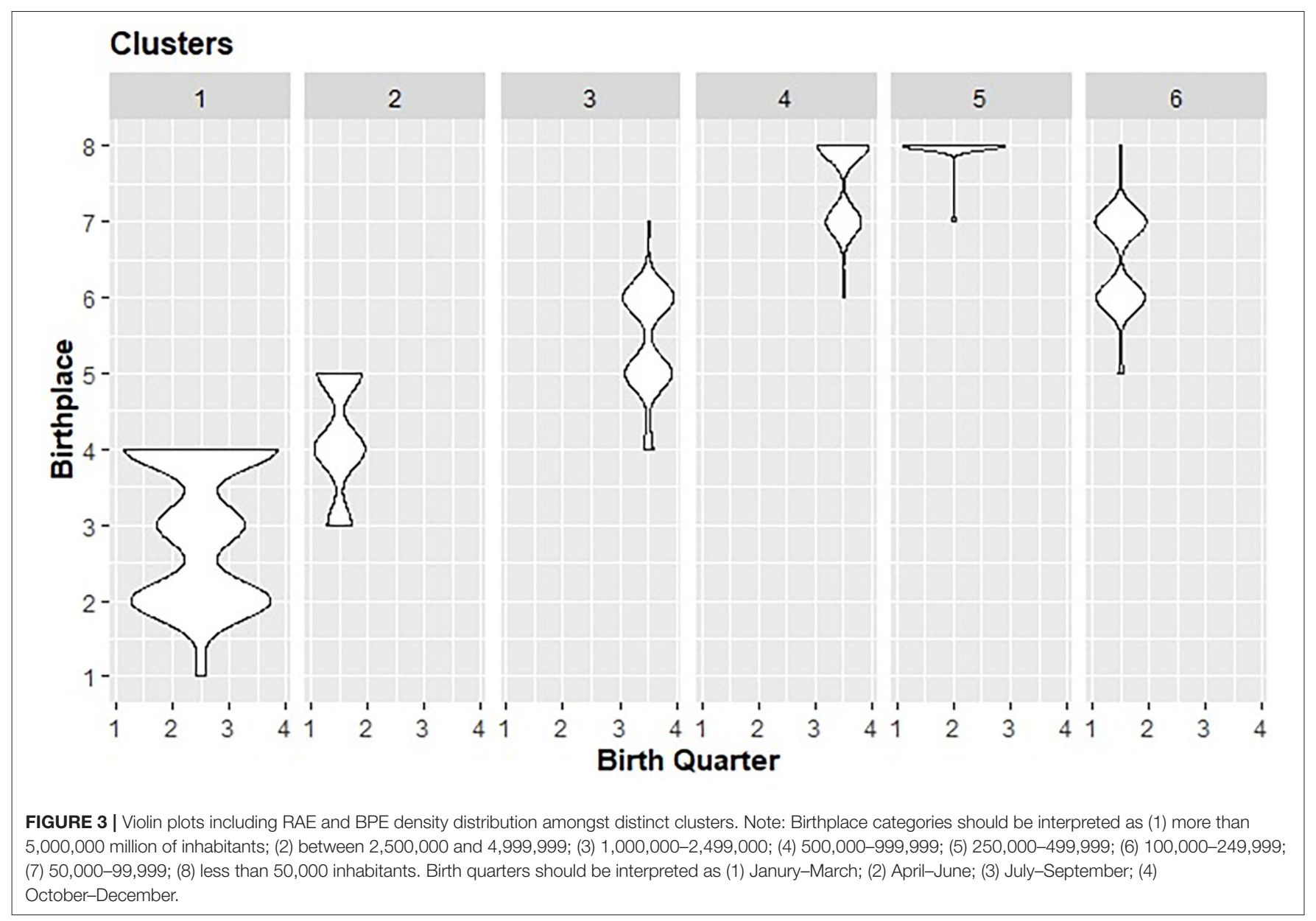

Simultaneously, playing more often against the same opponents can have a beneficial effect. In a team sport like basketball, having prior knowledge about your opponent strengths and weaknesses, can help the player to be more focused on improving and recognizing offensive and defensive game patterns to explore.

The second aim of the study was to examine the potential interaction between RAE and birthplace in players born in players born in the USA players. The only available study that hypothesized about this interaction was done by Bruner et al. (2011), however, no evidence of interaction was found. Interestingly, our data supported the theoretically driven hypothesis that USA players born in the bigger communities were relatively younger; players born in smaller communities integrated relatively older players; and NBA career performance was similar irrespectively of this interaction. According to Barker's "theory of behavior settings" (Barker, 1968) the number of people in a behavior setting will influence an individual's behavior. Thus, it could be expected that situations with fewer (i.e., smaller) or more than (i.e., bigger) the optimal number of participants needed to complete a task will result in different experiences for individuals involved. Thus, in light of our results, it may be hypothesized that smaller communities may be more likely to promote greater youth developmental opportunities for relatively older athletes, while bigger communities may be more appropriate environment for relatively younger athletes. Smaller cities seem to provide an environment in which, despite infrastructural resources, the number of teams and players being smaller, the need to select athletes based on their skill and maturation levels is higher. Consequently, RAE may be reduced or even removed in higher cities where these variables are not an issue, and therefore, seem to be more appropriate to further develop talent. Despite the interest and usefulness of these results for talent development, future studies are warranted to test this interaction.

The interaction little explains about the NBA career, however their experiences until getting there may have been influenced by these two factors. Both players who came from bigger cities or born in last quarters can be exposed to adverse experiences in their development, due to their disadvantageous status (McCarthy and Collins, 2014; McCarthy et al., 2016; Collins and Macnamara, 2017). However, they can perform a greater effort in the learning process, but also develop psychological skills becoming more able to overcome difficulties (Cobley et al., 2009; Gibbs et al., 2012), what can become a long-term advantage. The possible additional pressure experienced by the player born at the end of the year, can be an advantage in the long term. Undoubtedly, the challenge would be to know which of these two types of populations is likely to have a 
higher performance in the long term or to have longer and more successful sports careers.

The results of this study provide compelling evidence that contextual factors influence the likelihood to being selected to play in NBA. However, we must address potential limitations of our study, which must be acknowledged. First, the NBA Draft is an highly selective event, in which teams try to address their particular needs and not only look into de best prospect available in the board, regardless of the RAE and birthplace effects (Zhang et al., 2018). This logic is also observed in elite football that favors late maturing boys succeed in achieving elite level, despite not having benefited from a maturation bias through development process (Ostojic et al., 2014). That said, as the level of performance increases, performance in the short and medium term, considering the needs of the team can be decisive, more than other contextual factors.

Second, a challenge in birthplace effects studies is the analysis of population categories. We followed previous categorization used in studies with North-American athletes, but in each state, there are significant variations not only in terms of communities' sizes and also in population density. Researchers should be encouraged to explore methods by which to limit such variability, enabling stronger within-category consistency. This sizeable variation is even more critical in European countries, however, while we admit this limitation, we believe that this could trigger further studies that could highlight differences within European sport policies and youth development programs.

Additionally, it is important to acknowledge that birthplace does not always coincide with the athlete's place of development and that athletes may migrate among locations. For example, athletes born in small rural communities may move to larger urban centers during their childhood (Schorer et al., 2010). Another limitation may be the fact that this research is based on the interaction of the RAE and the birthplace effects in the short term, at a very specific moment such as the choice of the NBA Draft, but it would probably be more interesting to know the interaction of these effects in the long term, throughout the athlete's career, to know which players can have a longer sports career or have a higher performance.

\section{CONCLUSIONS}

The results of the current study confirm a biased distribution for players born in the initial months in each selection year against those born in smaller cities in the NBA. Evidence from this

\section{REFERENCES}

Arede, J., Esteves, P., Ferreira, A. P., Sampaio, J., and Leite, N. (2019a). Jump higher, run faster : effects of diversified sport participation on talent identification and selection in youth basketball identification and selection in youth basketball. $J$. Sports Sci. 00, 1-8. doi: 10.1080/02640414.2019.1626114

Arede, J., Ferreira, A. P., Gonzalo-Skok, O., and Leite, N. (2019b). Maturational development as key aspect in physiological performance and national team selection in elite male basketball players. Int. J. Sports Physiol. Perform. 14, 1-9. doi: 10.1123/ijspp.2018-0681 study is consistent with previous literature providing important considerations about the influence of contextual factors in achieving expertise in sport. Understanding the interaction between RAE and birthplace effects, can help researchers and practitioners on how to design sports systems and practice approaches to help nurture talent. Creating the most favorable environment for talent development is highly complex, due to performance multidimensionality. Delaying the selection of players until ages like those used in NBA Draft (mostly after 1920 years) is a suggestion systematically repeated by experts, but at the same time we must continue on a path to discover and integrate new variables in performance analysis. The results of this study represent an important contribution in this field since this interaction between contextual factors hasn't been described in the literature and in addition to helping us to know better the system, it can contribute to increase retention and improve coaches decision making.

\section{DATA AVAILABILITY STATEMENT}

The raw data supporting the conclusions of this article will be made available by the authors, without undue reservation.

\section{ETHICS STATEMENT}

The studies involving human participants were reviewed and approved by University of Trás-os-Montes and Alto Douro. Written informed consent for participation was not required for this study in accordance with the national legislation and the institutional requirements.

\section{AUTHOR CONTRIBUTIONS}

NL, JA, and XS: conceptualization. NL, JA, and XS: investigation. NL and JA: methodology. NL, XS, and JA: data curation. NL, JA, XS, JC-G, and AL: formal analysis. NL and JA: software. NL and XS: writing-original draft. NL, JA, JC-G, and AL: writingreview and editing: All authors contributed to the article and approved the submitted version.

\section{FUNDING}

The present study was supported by the national funding through the Portuguese Foundation for Science and Technology, I.P., under project UID04045/2020.
Baker, J, Schorer, J., Cobley, S., Schimmer, G., and Wattie, N. (2009). Circumstantial development and athletic excellence : the role of date of birth and birthplace. Eur. J. Sport Sci. 9, 329-339. doi: 10.1080/17461390902933812

Baker, J., and Logan, A. J. (2007). Developmental contexts and sporting success: birth date and birthplace effects in National Hockey League draftees 2000-2005. Br. J. Sports Med. 41, 515-517. doi: 10.1136/bjsm.2006.033977

Barker, R. G. (1968). Ecologicalpsychology: Concepts and Methods for Studying the Environment of Human Behavior. Stanford, CA: Stanford University Press.

Berry, J., Abernethy, B., and Côté, J. (2008). The contribution of structured activity and deliberate play to the development of expert perceptual 
and decision-making skill. J. Sport Exerc. Psychol. 30, 685-708. Retrieved from http://sgp.thefa.com//media/files/pdf/getintofootball/ fa_learning_youthmodule2/thecontributionofstructuredactivity.ashx/ TheContributionofStructuredActivity.pdf.

Bezuglov, E. N., Nikolaidis, P. T., Khaitin, V., Usmanova, E., Luibushkina, A., Repetiuk, A., et al. (2019). Prevalence of relative age effect in Russian Soccer : the role of chronological age and performance. Int. J. Environ. Res. Public Health 16:4055. doi: 10.3390/ijerph16214055

Bruner, M. W., MacDonald, D. J., Pickett, W., and Côté, J. (2011). Examination of birthplace and birthdate in world junior ice hockey players. J. Sports Sci. 29, 1337-1344. doi: 10.1080/02640414.2011.597419

Côté, J., MacDonald, D. J., Baker, J., and Abernethy, B. (2006). When "where" is more important than "when": birthplace and birthdate effects on the achievement of sporting expertise. J. Sports Sci. 24, 1065-1073. doi: $10.1080 / 02640410500432490$

Castillo, D., Perez-Gonzalez, B., Raya-Gonzalez, J., Fernandez-Luna, A., Burillo, P., and Lago-Rodriguez, A. (2019). Selection and promotion processes are not associated by the relative age effect in an elite Spanish soccer academy. PLoS ONE 14:e219945. doi: 10.1371/journal.pone.0219945

Cobley, S., Baker, J., Wattie, N., and McKenna, J. (2009). Annual age-grouping and athlete development: a meta-analytical review of relative age effects in sport. Sports Med. 39, 235-256. doi: 10.2165/00007256-200939030-00005

Collins, D. J., and Macnamara, A. (2017). Making champs and super-champscurrent views, contradictions, and future directions. Front. Psychol. 8:823. doi: 10.3389/fpsyg.2017.00823

Davids, K., and Baker, J. (2007). Genes, environment and sport performance: why the nature-nurture dualism is no longer relevant. Sports Med. 37, 961-980. doi: 10.2165/00007256-200737110-00004

De la Rubia, A., Calvo, J. L., Mon-López, D., and Lorenzo, A. (2020a). Impact of the relative age effect on competition performance in basketball : a qualitative systematic review. Int. J. Environ. Res. Public Health 17:8596. doi: 10.3390/ijerph17228596

De la Rubia, A., Lorenzo-Calvo, J., and Lorenzo, A. (2020b). Does the relative age effect influence short-term performance and sport career in team sports? A qualitative systematic review. Front. Psychol. 11:1947. doi: $10.3389 /$ fpsyg. 2020.01947

Ford, P., De Ste Croix, M., Lloyd, R., Meyers,R., Moosavi,M., Oliver, J., et al. (2011). The long-term athlete development model: Physiological evidence and application, J. Sports Sci. 29:4, 389-402, doi: 10.1080/02640414.2010.536849 AQ uncite

Fumarco, L., Gibbs, B. G., Jarvis, J. A., and Rossi, G. (2017). The relative age effect reversal among the National Hockey League elite. PLoS ONE 12:e0182827. doi: 10.1371/journal.pone.0182827

Gibbs, B. G., Jarvis, J. A., and Dufur, M. J. (2012). The rise of the underdog? The relative age effect reversal among Canadian-born NHL hockey players: a reply to Nolan and Howell. Int. Rev. Soc. Sport 47, 644-649. doi: $10.1177 / 1012690211414343$

Greco, P., Memmert, D., and Morales, J. (2010). The effect of deliberate play on tactical performance in basketball. Percept.Motor Skills 110, 1-8. doi: 10.2466/pms.110.3.849-856

Hancock, D. J., Coutinho, P., Côté, J., Mesquita, I., Hancock, D. J., Coutinho, P., et al. (2018). Influences of population size and density on birthplace effects. J. Sports Sci. 36, 33-38. doi: 10.1080/02640414.2016.1276614

Hellmann, F., Verdi, M., Junior, B. R., and Caponi, S. (2014). 50th anniversary of the declaration of Helsinki: the double standard was introduced. Arch. Med. Res. 45, 600-601. doi: 10.1016/j.arcmed.2014.10.005

Imtiaz, F., Hancock, D. J., Vierimaa, M., and Côté, J. (2014). Place of development and dropout in youth ice hockey. Int. J. Sport Exerc. Psychol. 12, 234-244. doi: 10.1080/1612197X.2014.880262

Ishigami, H. (2016). Relative age and birthplace effect in Japanese professional sports : a quantitative evaluation using a Bayesian hierarchical Poisson model. J. Sports Sci. 34, 143-154. doi: 10.1080/02640414.2015.1039462

Kaida, L., and Kitchen, P. (2020). It's cold and there's something to do : the changing geography of Canadian National Hockey League players' hometowns. Int. Rev. Sociol. Sport 55, 209-228. doi: 10.1177/1012690218789045

Koz, D., Fraser-Thomas, J., and Baker, J. (2012). Accuracy of professional sports drafts in predicting career potential. Scand. J. Med. Sci. Sports, 22, e64-69. doi: $10.1111 / j .1600-0838.2011 .01408 . x$
Leite, N., and Sampaio, J. (2012). Long-term athletic development across different age groups and gender from portuguese basketball players. Int. J. Sports Sci. Coach. 7, 285-300. doi: 10.1260/1747-9541.7.2.285

Lidor, R., Arnon, M., Maayan, Z., Gershon, T., and Côté, J. (2014). Relative age effect and birthplace effect in Division 1 female ballgame players-the relevance of sport-specific factors. Int. J. Sport Exerc. Psychol. 12, 19-33. doi: 10.1080/1612197X.2012.756232

Lidor, R., Côté, J., Arnon, M., Zeev, A., and Cohen-Maoz, S. (2010). Relative age and birthplace effects in Division 1 players-do they exist in a small country? Talent Dev. Excell. 2, 181-192.

MacDonald, D. J., Cheung, M., Côté, J., and Abernethy, B. (2009a). Place but not date of birth influences the development and emergence of athletic talent in American Football. J. Appl. Sport Psychol. 21, 80-90. doi: 10.1080/10413200802541868

MacDonald, D. J., King, J., Côté, J., and Abernethy, B. (2009b). Birthplace effects on the development of female athletic talent. J. Sci. Med. Sport 12, 234-237. doi: $10.1016 /$ j.jsams.2007.05.015

Mann, D. L., and van Ginneken, P. J. (2017). Age-ordered shirt numbering reduces the selection bias associated with the relative age effect, J. Sports Sci. 35:8, 784-790. doi: 10.1080/02640414.2016.1189588

McCarthy, N., and Collins, D. (2014). Initial identification and selection bias versus the eventual confirmation of talent: evidence for the benefits of a rocky road? J. Sports Sci. 32, 1604-1610. doi: 10.1080/02640414.2014.908322

McCarthy, N., Collins, D., and Court, D. (2016). Start hard, finish better : further evidence for the reversal of the RAE advantage. J. Sports Sci. 34, 1461-1465. doi: 10.1080/02640414.2015.1119297

Memmert, D., Baker, J., and Bertsch, C. (2010). Play and practice in the development of sport-specific creativity in team ball sports. High Ability Stud. 21, 3-18. doi: 10.1080/13598139.2010.488083

Moesch, K., Hauge, M. T., Wikman, J. M., and Elbe, A.-M. (2013). Making it to the top in team sports : start later, intensify, and be determined! Talent Dev. Excel $5,85-100$.

Musch, J., and Grondin, S. (2001). Unequal competition as an impediment to personal development : a review of the relative age effect in sport. Dev. Rev. 21, 147-167. doi: 10.1006/drev.2000.0516

Nakata, H., Akido, M., Naruse, K., and Fujiwara, M. (2017). Relative age effect in physical fitness among elementary and junior high school students. Percept. Motor Skills 124, 900-911. doi: 10.1177/0031512517722284

Olswang, L. B., and Prelock, P. A. (2015). Bridging the gap between research and practice: implementation science. J. Speech Lang. Hear Res, 58, S1818-S126. doi: 10.1044/2015_JSLHR-L-14-0305

Ostojic, S. M., Castagna, C., Calleja-González, J., Jukic, I., Idrizovic, K., and Stojanovic, M. (2014). The biological age of 14-year-old boys and success in adult soccer: do early maturers predominate in the top-level game? Res. Sports Med. (Print), 22, 398-407. doi: 10.1080/15438627.2014. 944303

Pennell, K., Cassidy, T., and Gilbert, W. (2017). The 'small town' effect on youth athletic development : insights from New Zealand 'touch.' Qual. Res. Sport Exerc. Health 9, 339-353. doi: 10.1080/2159676X.2017.1303789

Rada, A., Padulo, J., Jelaska, I., Ardigò, L., and Fumarco, L. (2018). Relative age effect and second-tiers : no second chance for later-born players. PLOS ONE 13:e0201795. doi: 10.1371/journal.pone.0201795

Rees, T., Hardy, L., Gu, A., Woodman, T., Montgomery, H., Laing, S., et al. (2016). The Great British Medalists Project : a review of current knowledge on the development of the world's best sporting talent. Sports Med. 46, 1041-1058. doi: 10.1007/s40279-016-0476-2

Rossing, N. N., Nielsen, A. B., Elbe, A., and Karbing, D. S. (2015). The role of community in the development of elite handball and football players in Denmark. Eur. J. Sport Sci. 16, 237-245. doi: 10.1080/17461391.2015.1009492

Sampaio, J., McGarry, T., Calleja-González, J., Jiménez Sáiz, S., Schelling, X., and Balciunas, M. (2015). Exploring game performance in the National Basketball Association using player tracking data. PLoS ONE 10:e0132894. doi: 10.1371/journal.pone. 0132894

Schorer, J., Baker, J., Lotz, S., and Büsch, D. (2010). Influence of early environmental constraints on achievement motivation in talented young handball players. Int. J. Sport Psychol. 41, 42-57.

Teramoto, M., Cross, C. L., Rieger, R. H., Maak, T. G., and Willick, S. E. (2017). Predictive validity of National Basketball Association draft 
combine on future performance. J. Strength Cond. Res. 32, 396-408. doi: 10.1519/JSC.0000000000001798

Till, K., and Baker, J. (2020). Challenges and [Possible] solutions to optimising talent identification and development in sport. Front. Psychol. 11:664. doi: 10.3389/fpsyg.2020.00664

Turnnidge, J., Hancock, D. J., and Côté, J. (2014). The influence of birth date and place of development on youth sport participation. Scand. J. Med. Sci. Sports 24, 461-468. doi: 10.1111/sms.12002

Wattie, N., Schorer, J., and Baker, J. (2018). Seeing the forest but not the trees : heterogeneity in community size effects in Canadian ice hockey players. J. Sports Sci. 36, 436-444. doi: 10.1080/02640414.2017.13 13444

Williams, A. M., Ford, P. R., Drust, B., Williams, A. M., Ford, P. R., and Drust, B. (2020). Talent identification and development in soccer since the millennium. J. Sports Sci. 38, 1199-1210. doi: 10.1080/02640414.2020.17 66647

Zaric, I., Kukic, F., Joviceci, N., Zaric, M., Markovic, M., Toskic, L., et al. (2020). Body height of elite basketball players : do taller basketball teams rank better at the FIBA World Cup? Int.J. Environ. Res. Public Health 17:3141. doi: 10.3390/ijerph17093141

Zhang, S., Lorenzo, A., Gómez, M., Mateus, N., Gonçalves, B., Sampaio, J., et al. (2018). Clustering performances in the NBA according to players' anthropometric attributes and playing experience and playing experience. $J$. Sports Sci. 36, 2511-2520. doi: 10.1080/02640414.2018.1466493

Conflict of Interest: The authors declare that the research was conducted in the absence of any commercial or financial relationships that could be construed as a potential conflict of interest.

Copyright (c) 2021 Leite, Arede, Shang, Calleja-González and Lorenzo. This is an open-access article distributed under the terms of the Creative Commons Attribution License (CC BY). The use, distribution or reproduction in other forums is permitted, provided the original author(s) and the copyright owner(s) are credited and that the original publication in this journal is cited, in accordance with accepted academic practice. No use, distribution or reproduction is permitted which does not comply with these terms. 